\title{
Substituição do milho e do feno de capim-tifton por palma forrageira. Produção de proteína microbiana e excreção de uréia e de derivados de purina em vacas lactantes ${ }^{1}$
}

\author{
Veronaldo Souza de Oliveira ${ }^{2}$, Marcelo de Andrade Ferreira ${ }^{3}$, Adriana Guim ${ }^{3}$, Elisa Cristina \\ Modesto ${ }^{3}$, Luiz Evandro Lima ${ }^{4}$, Fabiana Maria da Silva ${ }^{5}$ \\ ${ }^{1}$ Parte da tese de Doutorado do primeiro autor apresentada ao Programa de Doutorado Integrado em Zootecnia da UFRPE. Trabalho \\ financiado pelo CNPq. \\ 2 Programa de Pós-Graduação Integrado em Zootecnia da UFRPE-Recife-PE. \\ ${ }^{3}$ Departamento de Zootecnia/UFRPE. \\ 4 IPA \\ 5 Graduanda em Zootecnia/UFRPE. \\ * Bolsista do CNPq.
}

RESUMO - O experimento foi conduzido com os objetivos de estimar a produção e a eficiência de síntese de proteína microbiana utilizando-se a excreção total de derivados de purinas (DP) e avaliar as concentrações de uréia na urina, de uréia e N-uréia no plasma e no leite de vacas holandesas em lactação alimentadas com dietas formuladas com diferentes níveis ( 0 ; 12,$0 ; 25,0 ; 38,0$ e 51,0\%) de palma forrageira (Opuntia ficus indicaMill) em substituição total ao milho (Zea mays L.) e parcial ao feno de capim-tifton (Cynodon spp). Foram utilizadas cinco vacas holandesas distribuídas em um quadrado latino 5 x 5 . Cada período experimental teve duração de 17 dias, dez para adaptação dos animais à dieta e sete para coleta de dados. O volume urinário foi estimado em amostrasspotde urina obtidas 4 horas após a alimentação. O volume urinário (27,62 L), a excreção urinária de ácido úrico $(35,78 \mathrm{mmol} / \mathrm{dia})$, alantoína na urina $(288,42 \mathrm{mmol} / \mathrm{dia})$, alantoína no leite $(18,11 \mathrm{mmol} / \mathrm{dia})$ e alantoína total (306,54 mmol/dia), a excreção de derivados de purina total (342,33 mmol/dia) e de purinas absorvidas (350,03 $\mathrm{mmol} / \mathrm{dia})$, a síntese de proteína microbiana $(1.376,07 \mathrm{~g} / \mathrm{dia})$ e a eficiência da síntese de proteína microbiana $\left(115,38 \mathrm{~g} / \mathrm{kgNDT}_{\text {consumido }}\right)$ não foram afetados pela substituição do milho e do feno de tifton por palma na dieta. A excreção de uréia na urina ( $\mathrm{mg} / \mathrm{kg} \mathrm{PV})$ e as concentrações de uréia e $\mathrm{N}$-uréia no plasma $(\mathrm{mg} / \mathrm{dL})$ decresceram de forma linear, enquanto a excreção e as concentrações de uréia e $\mathrm{N}$-uréia no leite e de glicose plasmática não foram influenciadas pelos níveis de palma na dieta. O milho pode ser substituído integralmente e o feno, parcialmente, por palma forrageira em dietas para vacas holandesas em lactação, pois a substituição não afetou a produção de proteína microbiana ou as perdas do nitrogênio dietético pela excreção de uréia.

Palavras-chave: alantoína, creatinina, nitrogênio microbiano, volume urinário

\section{Effects of replacing of corn and Tifton hay with forage cactus on microbial protein synthesis and nitrogen metabolism in lactating dairy cows}

\footnotetext{
ABSTRACT- The objective of this trial was to evaluate the effect of replacing Tifton hay and corn with forage cactus (Opuntia ficus indica Mill) on microbial protein synthesis and efficiency and $\mathrm{N}$ metabolism in lactating Holstein cows. Diets contained (\% of DM): 0, 12.0, 25.0,38.0, or 51.0\%) of forage cactus. Five Holstein cows were randomly assigned to treatments in a 5 x 5 Latin square design. Each experimental period lasted 17 days with 10 days for diet adaptation and seven days for data and sample collection. Urinary volume was estimated based on creatinine excretion in spot urine samples obtained four hours after feeding. Urinary volume $(27.62 \mathrm{~L})$, urinary excretion of uric acid $(35.78 \mathrm{mmol} / \mathrm{day})$ and allantoin $(288.42 \mathrm{mmol} / \mathrm{day})$, allantoin in milk (18.11 mmol/day), total allantoin (306.54 mmol/day), total excretion of purine derivatives ( $342.33 \mathrm{mmol} / \mathrm{day})$, absorbed purines ( $350.03 \mathrm{mmol} / \mathrm{day})$, microbial protein synthesis $(1376.07 \mathrm{~g} / \mathrm{day})$ and efficiency $(115.38 \mathrm{~g} / \mathrm{kgNDT})$ were not affected by increasing the levels of forage cactus in the diet. The urinary excretion of urea $(\mathrm{mg} / \mathrm{kg} \mathrm{BW})$ and the concentrations of urea and urea- $\mathrm{N}$ in plasma $(\mathrm{mg} / \mathrm{dL})$ decreased linearly while the concentrations of urea and urea- $\mathrm{N}$ in milk were not affected when the levels of forage cactus were increased in the diet. Corn can be completely replaced with forage cactus because microbial protein synthesis was not changed and urinary excretion of urea decreased linearly. However, Tifton hay was necessary in the diet to maintain microbial production.
}

Key Words: allantoin, creatinine, microbial nitrogen, urinary volume 


\section{Introdução}

Durante muito tempo, acreditou-se que era vantajoso que a degradação da proteína dietética em ruminantes ocorresse no intestino delgado, em vez de ser degradada pela fermentação ruminal. Admitia-se que, ao evitar perdas no processo fermentativo, maior quantidade de proteína e energia seria economizada, o que resultaria em melhora do desempenho animal. Atualmente, sabe-se que o aporte maior dos aminoácidos que chegam ao duodeno para atender às exigências dos ruminantes é proveniente das proteínas microbianas sintetizadas no rúmen, da proteína dietética que não é degradada no rúmen e, em menor quantidade, da contribuição endógena das células de descamação (NRC, 2001). Segundo Sniffen \& Robison (1987), a proteína microbiana sintetizada no rúmen pode fornecer 40 a $80 \%$ dos aminoácidos requeridos pelos ruminantes. Visando maior eficiência na produção de ruminantes, procura-se viabilizar ao máximo a produção de proteína microbiana ruminal.

As recomendações mais promissoras para vacas leiteiras de alta produção parecem ser suprir doses adequadas de proteína degradável no rúmen (PDR) para maximizar a síntese de proteína microbiana e reduzir a inclusão de fontes ricas em proteína degradável no rúmen (PNDR) de alta qualidade. A importância de determinar a contribuição da proteína microbiana para bovinos tem sido objeto de muitos estudos. Métodos baseados na utilização da excreção de derivados de purinas na urina são menos invasivos que a utilização de animais fistulados. Entretanto, segundo Chen \& Gomes (1992), esses métodos requerem coleta total de urina, mas podem ser simplificados e utilizados a campo.

Oliveira et al. (2001) e Silva et al. (2001) utilizaram a creatinina como marcador para estimativa do volume urinário em vacas leiteiras, com coleta spot de urina, e concluíram que o volume urinário pode ser estimado com este tipo de coleta, que possibilita avaliar a excreção de derivados de purina e de outros compostos sem a necessidade da coleta total de urina.

No método de avaliação pela excreção de derivados de purina (DP), assume-se que o fluxo duodenal de ácidos nucléicos é predominantemente de origem microbiana. Além disso, após digestão intestinal dos nucleotídeos de purinas, as bases nitrogenadas adenina e guanina são catabolizadas e excretadas proporcionalmente na urina como DP, principalmente alantoína, mas também como xantina, hipoxantina e ácido úrico (Perez et al., 1996; Chen \& Gomes, 1992).

A concentração de $\mathrm{N}$-amoniacal necessária para maximizar a síntese de proteína microbiana ainda é motivo de controvérsia. Segundo Santos et al. (1998), o nível ótimo de nitrogênio amoniacal ruminal varia de acordo com a disponibilidade de carboidratos fermentáveis no rúmen. Zeoula et al. (2002) afirmaram que a sincronização entre as fontes de carboidratos e nitrogênio pode acarretar maximização da eficiência microbiana e diminuição da perda de nitrogênio na forma de $\mathrm{N}-\mathrm{NH}_{3}$. De acordo com Valadares Filho \& Cabral (2002), no entanto, a taxa na qual a energia é disponibilizada na dieta é o fator mais limitante da síntese de proteína microbiana. $\mathrm{O}$ fornecimento de quantidades moderadas de CNF, geralmente, aumenta o fluxo de $\mathrm{N}$ microbiano para o abomaso, desde que não haja limitação de $\mathrm{N}$ disponível no rúmen.

A proteína dietética é amplamente degradada no rúmen, que gera grande quantidade de amônia, que, em parte, é incorporada pelos microrganismos (principalmente aqueles que degradam carboidratos estruturais) na forma de proteína microbiana. No entanto, em muitas ocasiões, a proporção de amônia liberada é superior à capacidade de utilização pelos microrganismos (Santos et al., 2001), o que resulta em elevada concentração endógena de uréia no sangue, no leite e na urina. A concentração de uréia no leite reflete a concentração de uréia no plasma, portanto, são altamente correlacionados $(0,88 ; 0,98)$, o que torna essa variável um importante indicador do metabolismo protéico em vacas (Roseler et al., 1993; Broderick \& Clayton, 1997; Jonker et al., 1998).

O excesso de proteína degradável no rúmen (PDR) em dietas para vacas leiteiras, além de não ser eficientemente utilizado para síntese de proteína microbiana, contribui para perdas substanciais de $\mathrm{N}$ pela excreção urinária (Hristov et al., 2004). Nesse sentido, Valadares et al. (1997) afirmaram que a concentração plasmática de uréia está positivamente relacionada à ingestão de compostos nitrogenados. Esta afirmativa foi confirmada por Broderick (2003), que verificou aumento linear na excreção da uréia do leite e de nitrogênio na urina e decréscimo na eficiência do nitrogênio com o aumento do nível de proteína na dieta de vacas leiteiras.

Roseler et al. (1993) também relataram que a concentração de N-uréico no plasma (NUP) afeta diretamente as de $\mathrm{N}$-uréico do leite (NUL), visto que a uréia pode se difundir facilmente do sangue para o leite através dos tecidos epiteliais da glândula mamária (Gustafsson \& Palmquist, 1993; Broderick \& Clayton, 1997). Conseqüentemente, a concentração de NUL pode ser utilizada como estimativa do NUP sem a necessidade de coleta e exame de amostras do sangue (Roseler et al., 1993). Como a coleta de leite durante a ordenha é fácil, a determinação da concentração de uréia no leite pode ser feita com boa acurácia por métodos 
enzimáticos (kit comerciais) ou físicos. Alguns autores têm sugerido que a concentração de NUL pode ser utilizada como diagnóstico para monitorar a eficiência de utilização do nitrogênio nos rebanhos leiteiros e controlar a emissão de compostos nitrogenados no meio ambiente (Jonker etal., 1998; Kauffman \& St.Pierre, 2001; Nousiainen et al., 2004).

Os objetivos neste trabalho foram avaliar os efeitos da substituição total do farelo de milho e parcial do feno de capim-tifton por palma forrageira em dietas para vacas holandesas em lactação sobre a estimativa da síntese de proteína microbiana e as concentrações de uréia na urina, de uréia e N-uréia no plasma e no leite e as concentrações de glicose plasmática.

\section{Material e Métodos}

O experimento foi conduzido na Estação Experimental de São Bento do Una, pertencente à Empresa Pernambucana de Pesquisa Agropecuária - IPA, no período de setembro a novembro de 2004. As temperaturas mais elevadas são observadas nos meses de novembro a janeiro (superiores a $30^{\circ} \mathrm{C}$ ). A temperatura média mensal varia de 21,7 a $25^{\circ} \mathrm{C}$ e a mínima, de 15,7 a $15,2^{\circ} \mathrm{C}$. A umidade relativa média do ar é de 66\% (FIDEPE, 1982).

Foram utilizadas cinco vacas holandesas $(583 \pm 7,07 \mathrm{~kg}$ de PV) aos 110 dias de lactação no início do experimento. Os animais foram alojados em baias individuais com cerca de arame farpado e piso de terra batida, com área coberta de $6 \mathrm{~m}^{2}$, dotadas de cocho para fornecimento e controle do consumo de alimentos e bebedouro para fornecimento de água à vontade.

Os animais foram distribuídos em quadrado latino $5 \times 5$, com cinco animais, cinco níveis de palma forrageira $(0,00$; 12,$00 ; 25,00 ; 38,00$ e $51,00 \%$ na MS da dieta) e cinco períodos experimentais. Cada período teve duração de 17 dias, dez para adaptação dos animais às dietas e sete para coleta dos dados e das amostras. O fornecimento da dieta foi feito duas vezes ao dia, na forma de ração completa, para permitir sobras de 5 a $10 \%$ do total da MS fornecida.

$\mathrm{Na}$ Tabela 1 são apresentadas as composições bromatológicas dos ingredientes e, na Tabela 2, as composições percentual e química das dietas experimentais.

Durante o período de coleta, amostras spot (coleta única) de urina foram obtidas no 11 o dia de cada período experimental, aproximadamente 4 horas após a alimentação, durante micção espontânea. Uma alíquota de $10 \mathrm{~mL}$ de urina foi diluída em $40 \mathrm{~mL}$ de ácido sulfúrico de normalidade 0,036 . Em seguida, foi determinado o $\mathrm{pH}$ e, se necessário, o $\mathrm{pH}$ foi ajustado para valores inferiores a 3, com gotas de ácido
Tabela 1 - Composição química dos ingredientes das dietas experimentais, com base na MS

Table 1 - Chemical composition of ingredients of the experimental diets, $\%$ of $D M$

\begin{tabular}{|c|c|c|c|c|}
\hline \multirow[t]{2}{*}{$\begin{array}{l}\text { Item } \\
\text { Item }\end{array}$} & \multicolumn{4}{|c|}{$\begin{array}{l}\text { Alimento } \\
\text { Feed }\end{array}$} \\
\hline & $\begin{array}{c}\text { Palma } \\
\text { Forage cactus }\end{array}$ & $\begin{array}{l}\text { Feno de } \\
\text { tifton } \\
\text { Tifton } \\
\text { hay }\end{array}$ & $\begin{array}{l}\text { Milho } \\
\text { moído } \\
\text { Cracked } \\
\text { corn }\end{array}$ & $\begin{array}{c}\text { Farelo de } \\
\text { soja } \\
\text { Soybean } \\
\text { meal }\end{array}$ \\
\hline $\operatorname{MS}(\%)(D M \%)$ & 9,43 & 90,72 & 88,33 & 89,12 \\
\hline $\mathrm{PB}^{1}(C P)$ & 4,2 & 9,74 & 9,05 & 51,45 \\
\hline $\mathrm{FDN}^{1}(N D F)$ & 35,81 & 77,61 & 15,61 & 15,30 \\
\hline $\mathrm{FDA}^{1}(A D F)$ & 26,03 & 39,85 & 8,46 & 12,57 \\
\hline $\mathrm{EE}^{1}(E E)$ & 1,36 & 2,17 & 4,36 & 2,19 \\
\hline $\mathrm{MM}^{1}(A s h)$ & 8,29 & 9,33 & 2,74 & 7,29 \\
\hline $\mathrm{CT}^{1}(T C)$ & 86,15 & 78,76 & 84,02 & 39,07 \\
\hline $\mathrm{CNF}^{1}(N F C)$ & 50,34 & 1,15 & 68,41 & 23,77 \\
\hline
\end{tabular}

$1 \% \mathrm{MS}(\% D M)$.

Tabela 2 - Proporção dos ingredientes e composição bromatológica das dietas

Table 2 - Ingredient and chemical composition of the experimental diets

\begin{tabular}{|c|c|c|c|c|c|}
\hline \multirow[b]{2}{*}{$\begin{array}{l}\text { Alimento } \\
\text { Feed }\end{array}$} & \multicolumn{5}{|c|}{$\begin{array}{c}\text { Nível de inclusão de palma (\%) } \\
\text { Forage cactus level }(\%)\end{array}$} \\
\hline & 0,0 & 12,0 & 25,0 & 38,0 & 51,0 \\
\hline Palma & 0,00 & 12,00 & 25,00 & 38,00 & 51,00 \\
\hline $\begin{array}{l}\text { Forage cactus } \\
\text { Feno } \\
\text { Hay }\end{array}$ & 67,42 & 58,75 & 49,44 & 39,02 & 27,85 \\
\hline $\begin{array}{l}\text { Milho moído } \\
\text { Cracked corn }\end{array}$ & 16,39 & 12,12 & 8,11 & 3,88 & 0,00 \\
\hline Farelo de soja & 14,19 & 15,13 & 15,45 & 17,0 & 19,15 \\
\hline $\begin{array}{l}\text { Soybean meal } \\
\text { Mistura mineral } \\
\text { Mineral mix }\end{array}$ & 2,00 & 2,00 & 2,00 & 2,00 & 2,00 \\
\hline
\end{tabular}

Composição químico-bromatológica

Chemical composition

\begin{tabular}{lrrrrr}
\hline MS $(\%)(D M)$ & 90,25 & 44,50 & 28,72 & 21,20 & 16,81 \\
MO $(O M)^{1}$ & 92,22 & 92,08 & 91,98 & 91,87 & 91,78 \\
PB $(C P)^{1}$ & 15,18 & 14,94 & 14,76 & 14,68 & 14,84 \\
EE $^{1}$ & 1,85 & 1,82 & 1,79 & 1,76 & 1,73 \\
${\text { FDN }(N D F)^{1}}^{1}$ & 57,51 & 54,23 & 50,69 & 47,14 & 43,13 \\
FDA $(A D F)^{1}$ & 29,88 & 29,17 & 28,30 & 27,43 & 26,34 \\
CNF $(N F C)^{1}$ & 15,06 & 18,56 & 22,46 & 26,16 & 30,02 \\
NDT $(T D N)(\%)^{1}$ & 59,85 & 61,69 & 60,70 & 61,63 & 61,69 \\
CT $(T C)(\%)^{1}$ & 72,57 & 71,85 & 73,15 & 73,30 & 73,15 \\
PDR $(R D P)^{1}$ & 9,18 & 9,46 & 9,31 & 9,45 & 9,46 \\
\hline
\end{tabular}

$1 \% \mathrm{MS}(\% \mathrm{DM})$.

sulfúrico concentrado. As amostras foram armazenadas a $-20^{\circ} \mathrm{C}$ e, posteriormente, analisadas quanto às concentrações de creatinina, uréia, alantoína e ácido úrico.

Na mesma ocasião, foram coletadas amostras de sangue de cada animal, por punção da veia mamária, utilizando-se tubos vacutainer de $10 \mathrm{~mL}$ com anticoagulante. As amostras foram imediatamente centrifugadas a $5.000 \mathrm{rpm}$ durante 15 
minutos. O plasma foi acondicionado em tuboseppendorf e armazenado a $-20^{\circ} \mathrm{C}$ para posterior análise de uréia, creatinina e glicose.

Amostras de leite das duas ordenhas de cada animal foram coletadas no 11 o, 150 e $16^{\circ}$ dias de cada período experimental, sendo homogeneizadas e analisadas quanto aos teores de gordura. Uma alíquota de $10 \mathrm{~mL}$ de leite foi misturada com $5 \mathrm{~mL}$ de ácido tricloroacético a $25 \%$, filtrada em papel-filtro e armazenada a $-20^{\circ} \mathrm{C}$ para análises de uréia e alantoína.

As análises de uréia no plasma, na urina e no leite desproteínado; de creatinina na urina e no plasma; de glicose no plasma e de ácido úrico na urina foram feitas utilizando-se kits comerciais (Doles), segundo orientações técnicas do fabricante.

As análises de alantoína na urina e no leite desproteinado foram feitas pelo método colorimétrico, proposto por Fugihara et al. (1987), descrito por Chen \& Gomes (1992).

O volume urinário foi estimado para cada animal, multiplicando-se o respectivo peso vivo pela excreção diária de creatinina ( $\mathrm{mg} / \mathrm{kg}$ de PV) e dividindo-se o produto pela concentração de creatinina $(\mathrm{mg} / \mathrm{L})$ na amostra spot. Para obtenção da excreção diária de creatinina por kg de PV, adotou-se a média de $25 \mathrm{mg} / \mathrm{kg}$ PV obtida dos estudos de Vala dares et al. (1999); Silva et al. (2001) e Oliveira et al. (2001).

A excreção total de DP foi calculada pela soma das quantidades de alantoína excretada na urina e no leite e pela excreção de ácido úrico na urina, expressos em mmol/dia.

As purinas absorvidas (PA) (X, mmol/dia) foram calculadas a partir da excreção de DP (Y, mmol/dia), pela equação $\mathrm{X}=\{\mathrm{Y}-(0,385 \times \mathrm{PV} 0,75)\} / 0,85$, em que 0,85 é a recuperação de purinas absorvidas como DP; e 0,385 $\mathrm{PV}^{0,75}$, a contribuição endógena para a excreção de purinas (Verbic et al., 1990).

A síntese ruminal de nitrogênio ( $\mathrm{Y}, \mathrm{gN} / \mathrm{dia}$ ) foi estimada a partir das PA (X, mmol/dia), mediante modificação da equação descrita por Chen \& Gomes (1992), pela substituição da relação Npurina:Ntotal nas bactérias $(0,116)$ por 0,134, conforme descrito por Valadares et al. (1999). Assim, obteve-se a equação $\mathrm{Y}=70 \mathrm{X} / 0,83$ x 0,134 x 1000, em que 70 é o nitrogênio de purinas $(\mathrm{mgN} / \mathrm{mol}) ; 0,134$, a relação $\mathrm{N}$ purina: $\mathrm{N}$ total das bactérias; e 0,83 , a digestibilidade das purinas microbianas.

A eficiência da síntese de nitrogênio microbiano (ESNmic) foi calculada pela quantidade de Nmic sintetizado pelo consumo de matéria orgânica aparentemente digerida no rúmen (CMODR). ESNmic $(\mathrm{g} / \mathrm{kg})=\mathrm{SNmic}(\mathrm{g}) / \mathrm{CMODR}$ $(\mathrm{kg})$, em que CMODR = CMO x DAMOx0,65 (ARC, 1980);
$\mathrm{CMO}=$ consumo de matéria orgânica digestível; e DAMO = digestibilidade aparente da matéria orgânica. A estimativa da proteína bruta microbiana (EPBmic) foi obtida multiplicando-se a SNmic x 6,25. A eficiência de síntese foi calculada utilizando-se a fórmula: ESPBmic $(\mathrm{g} / \mathrm{kg})=\operatorname{EPBmic}(\mathrm{g}) /$ CNDT $(\mathrm{kg})$, em que CNDT = consumo de nutrientes digestíveis totais.

Os dados foram submetidos às análises de variância e regressão utilizando-se o sistema de Análises Estatísticas e Genéticas - SAEG (UFV, 1998).

Os critérios utilizados para escolha do modelo foram a significância dos coeficientes de regressão e o coeficiente de determinação $\left(\mathrm{r}^{2}\right)$, obtido pela relação entre a soma dos quadrados da regressão e a soma de quadrados dos tratamentos e o fenômeno biológico.

\section{Resultados e Discussão}

$\mathrm{Na}$ Tabela 3 encontram-se os dados referentes ao volume urinário, à excreção de derivados de purina e à síntese de nitrogênio microbiano.Não houve efeito significativo $(\mathrm{P}>0,05)$ da dieta sobre as estimativas do volume urinário determinado pelo indicador metabólico creatinina, comprovando que a excreção de creatinina na urina não foi afetada pelos níveis de palma forrageira nas dietas. Esses resultados justificam o uso da creatinina como indicador eficiente na coleta spot de urina para determinação do volume urinário em vacas leiteiras. O volume urinário médio foi de 27,62 L/dia, próximo ao verificado por Melo (2004), de 23,94 L/dia (coleta spot) em vacas holandesas em lactação alimentadas com dietas contendo palma forrageira.

O NRC (2001) reportou que aumento de 18 para $30^{\circ} \mathrm{C}$ na temperatura provoca elevação de $29 \%$ no consumo de água e de $15 \%$ nas excreções urinárias. Segundo esse conselho, a perda de água via excreção urinária em relação ao total de água consumida varia de 15 a $21 \%$ em vacas em lactação. A estimativa do volume médio de água excretada via urina por meio do indicador metabólico creatinina foi de $21,1 \%$ em relação ao consumido (130,92 L/dia).

O maior volume urinário observado nesta pesquisa pode estar relacionado ao estresse térmico sofrido pelos animais durante o período experimental (setembro a dezembro/ 2004, período em que as temperaturas médias na região ultrapassam $30^{\circ} \mathrm{C}$ nas horas mais quentes do dia), que pode ter levado os animais a aumento do consumo de água para saciar a sede e dissipar o calor corpóreo. Aumento no consumo de água foi constatado por Arnaud et al. (2005), na mesma época do ano, em estudo com esses mesmos animais. Esses autores avaliaram o comportamento ingestivo 
Tabela 3 - Estimativas do volume urinário (VUE), da excreção urinária de creatinina (EuCR), ácido úrico (EuAU) e alantoína na urina (ALu), no leite $(A L I)$ e alantoína total (ALt), excreção de derivados de purina total (EDPt) e de purinas absorvidas (Pa), síntese microbiana de nitrogênio (SNmic) e proteína (SPBmic) e eficiência da síntese microbiana de nitrogênio (ESNmic) e proteína bruta (ESPBmic) em vacas holandesas alimentadas com dietas contendo palma forrageira

Table 3 - Average values of urinary volume (UV), urinary excretion of creatinine (UECR), uric acid (UA) and allantoin (ALu), allantoin in milk (Alm), total allantoin (TAL), total purine derivatives excretion (TPDE), absorbed purines (Pa) and microbial nitrogen synthesis (MNS) and protein (MSP), microbial nitrogen synthesis efficiency (NSE), microbial protein synthesis efficiency (MPSE) according to different levels of forage cactus in the diet

\begin{tabular}{|c|c|c|c|c|c|c|c|c|c|}
\hline & \multicolumn{5}{|c|}{$\begin{array}{l}\text { Nível de inclusão de palma (\%MS) } \\
\text { Forage cactus level }(\% D M)\end{array}$} & \multirow[t]{2}{*}{ CV (\%) } & \multirow[t]{2}{*}{ ER } & \multicolumn{2}{|c|}{$\mathrm{P}$} \\
\hline & 0,0 & 12,0 & 25,0 & 38,0 & 51,0 & & & $\mathrm{~L}$ & $\mathrm{Q}$ \\
\hline $\begin{array}{l}\operatorname{VUE}(\mathrm{L})^{1} \\
U V\end{array}$ & 29,32 & 30,17 & 24,59 & 27,12 & 26,91 & 19,05 & $\hat{y}=27,62$ & NS & NS \\
\hline $\begin{array}{l}\operatorname{EuCR}(\mathrm{mg} / \mathrm{dl}) \\
\operatorname{UECR}(\mathrm{mg} / \text { day })\end{array}$ & 54,86 & 51,15 & 59,02 & 57,40 & 54,39 & 15,45 & $\hat{y}=55,36$ & NS & NS \\
\hline $\begin{array}{l}\text { EuAU }(\mathrm{mmol})^{1} \\
U E A U(m m o l)^{1}\end{array}$ & 27,31 & 41,76 & 31,23 & 35,62 & 42,98 & 23,95 & $\hat{\mathrm{y}}=35,78$ & NS & NS \\
\hline $\begin{array}{l}\mathrm{ALu}(\mathrm{mmol})^{1} \\
A L u(\mathrm{mmol})\end{array}$ & 256,89 & 323,42 & 323,52 & 266,44 & 271,86 & 34,64 & $\hat{y}=288,42$ & NS & NS \\
\hline $\begin{array}{l}\mathrm{ALl}(\mathrm{mmol})^{1} \\
\operatorname{Alm}(\mathrm{mmol})\end{array}$ & 17,66 & 19,21 & 17,90 & 18,93 & 16,86 & 21,01 & $\hat{\mathrm{y}}=18,11$ & NS & NS \\
\hline $\begin{array}{l}\text { ALt }(\mathrm{mmol})^{1} \\
T A L(m m o l)^{1}\end{array}$ & 274,56 & 342,63 & 341,43 & 285,37 & 288,72 & 32,48 & $\hat{y}=306,54$ & NS & NS \\
\hline $\begin{array}{l}\text { EDPt }(\mathrm{mmol})^{1} \\
T P D E(m m o l)^{1}\end{array}$ & 301,88 & 384,40 & 372,66 & 320,99 & 331,71 & 29,74 & $\hat{y}=342,33$ & NS & NS \\
\hline $\begin{array}{l}\mathrm{Pa}(\mathrm{mmol})^{1} \\
\mathrm{~Pa}(\mathrm{mmol})^{1}\end{array}$ & 301,91 & 401,66 & 385,18 & 324,40 & 337,01 & 34,34 & $\hat{\mathrm{y}}=350,03$ & NS & NS \\
\hline $\begin{array}{l}\mathrm{SNmic}(\mathrm{g})^{1} \\
M N S(g)^{l}\end{array}$ & 189,90 & 252,64 & 242,28 & 204,04 & 211,98 & 34,34 & $\hat{y}=220,17$ & NS & NS \\
\hline $\begin{array}{l}\operatorname{SPBmic}(\mathrm{g})^{1} \\
\operatorname{MSP}(g)^{l}\end{array}$ & $1.186,91$ & $1.579,04$ & $1.514,25$ & $1.275,30$ & $1.324,87$ & 34,34 & $\hat{y}=1376,07$ & NS & NS \\
\hline $\begin{array}{l}\text { ESNmic }(\mathrm{g}) \\
\operatorname{ESNmic}(g)\end{array}$ & 23,03 & 28,39 & 29,93 & 27,23 & 31,96 & 36,35 & $\hat{\mathrm{y}}=28,11$ & NS & NS \\
\hline $\begin{array}{l}\text { ESPBmicr }(\mathrm{g} / \mathrm{kgNDT}) \\
\operatorname{MPSE}(g / \mathrm{kg} T D N)\end{array}$ & 94,66 & 112,82 & 124,35 & 112,20 & 132,87 & 36,70 & $\hat{y}=115,38$ & NS & NS \\
\hline
\end{tabular}

1 por dia (per day); NS = não-significativo (not significant).

e aspectos fisiológicos e verificaram consumo médio total de água de 130,92 kg/dia, ou seja, 43,38 kg/dia a mais em relação aos $87,53 \mathrm{~kg} /$ dia preconizados pelo NRC (2001), ressaltando-se que só a água proveniente da palma na dieta com $51 \%$ dessa forrageira representou $72,8 \%$ do total de água consumida. Volumes urinários médios inferiores $(12,47$; 11,87 e 10,05 L/dia) foram observados por Oliveira et al. (2001), Silva et al. (2001) e Mendonça et al. (2004), respectivamente, em pesquisas com vacas leiteiras na Região Sudeste do Brasil, o que pode estar relacionado às temperaturas mais amenas encontradas nessa região.

As excreções urinárias de ácido úrico também não foram influenciadas pela inclusão de palma na dieta e representaram 9,$04 ; 10,86 ; 8,38 ; 11,09$ e $12,95 \%$ das excreções totais dos derivados de purina na urina (média de 10,46\%). Segundo Johnson et al. (1998), a relação entre ácido úrico e derivados de purina na urina pode variar conforme a dieta e o estado fisiológico do animal. Os valores encontrados foram próximos aos descritos por Giesecke et al. (1994), Silva et al. (2001), Oliveira et al. (2001) e Souza et al. (2006), de 10,$6 ; 10,83 ; 10,52$ e $11,8 \%$, respectivamente.

Do mesmo modo, as excreções urinárias de alantoína não foram influenciadas pela inclusão de palma na dieta, sendo obtido valor médio de 288,42 mmol/dia, correspondente a $84,25 \%$ da excreção dos derivados totais de purina. Esse percentual foi próximo aos verificados por Vagnoni \& Broderick (1997), Silva et al. (2001) e Souza et al. (2006), de 86,$6 ; 71,90$ a 86,10 e $82,24 \%$, respectivamente.

A excreção média de alantoína no leite foi de $18,11 \mathrm{mmol} /$ dia e também não foi influenciada pelas dietas. Este fato pode ser explicado pela produção média de leite, bastante semelhante entre os animais utilizados no experimento $(20,34 ; 20,20 ; 21,78 ; 20,58$ e $20,35 \mathrm{~kg} / \mathrm{dia})$, pois, segundo Gonda \& Linderberg (1997), a produção de leite 
influencia a determinação da concentração e da quantidade da alantoína excretada no leite. A pouca variação nos percentuais protéicos e energéticos nas dietas utilizadas pode ter também favorecido esses resultados (Tabela 2).

A excreção média de alantoína no leite em relação à excreção total de derivados de purinas correspondeu a $5,3 \%$ e ficou entre os valores mínimos e máximos relatados por Souza et al. (2006), Silva et al. (2001), Oliveira et al. (2001) e Valadares et al. (1999), de 5,7 e 6,2; 3,37 e 4,49;4,42 e 5,23\%; e 4,2 a 5,7\%, independentemente das dietas utilizadas. A adição de palma nas dietas não influenciou os valores de alantoína excretada na urina e no leite; os respectivos percentuais de excreção, em relação à excreção total de alantoína, pouco variaram, ficando muito próximos aos observados na literatura.

As excreções totais de derivados de purina (média de $342,33 \mathrm{mmol} / \mathrm{dia})$ não foram influenciadas $(\mathrm{P}>0,05)$ pela inclusão de palma forrageira nas dietas. Como não houve influência da inclusão de palma nos derivados de purinas (ácido úrico, alantoína no leite e na urina), essa ausência de variação pode ser justificada pelos valores estimados das excreções totais de derivados de purinas. Melo et al. (2004), mesmo encontrando valor médio superior (448 mmol/dia) para as excreções totais de derivados de purina em vacas leiteiras alimentadas com dietas contendo palma e caroço de algodão, não observaram influência da dieta sobre essa variável. Essa variação entre os valores encontrados e os descritos na literatura pode estar relacionada a vários fatores, como o balanceamento da dieta, a presença de fontes de nitrogênio não-protéico (NNP) nas dietas e a produção de leite dos animais.

Os valores da estimativa das purinas absorvidas e da síntese microbiana de nitrogênio e proteína seguiram a mesma tendência das excreções totais dos derivados de purina, visto que a determinação dessas variáveis é calculada a partir dos valores dessa excreção. A ausência de variação dos valores estimados das sínteses microbianas de nitrogênio e PB com a oferta das dietas contendo palma pode ser explicada pela presença na dieta de uma fonte protéica com PDR (farelo se soja). Esse fato fez com que houvesse nitrogênio suficientemente disponível para o crescimento microbiano no rúmen, mesmo com a redução linear do CPB $(3,27 ; 3,30 ; 3,06 ; 2,80$ e 2,53 kg/dia). Esta hipótese é fortalecida pelos percentuais médios de PDR das dietas experimentais (Tabela 2 ), muito próximos aos estimados pela equação do NRC (2001), de 9,0;8,95; 9,02; 8,84 e $8,96 \%$, respectivamente.

O sincronismo energético-protéico das dietas possivelmente foi mantido, apesar da substituição total da fonte energética do amido (milho) pelos CNF presentes na palma.
Embora não se tenha determinado e quantificado a composição de CNF na palma forrageira, Melo et al. (2003) atribuíram a presença de $23,3 \%$ ao teor de pectina na palma. Provavelmente, a elevada degradabilidade ruminal desse carboidrato em relação ao amido manteve um ambiente ruminal favorável à síntese de nitrogênio e ao desenvolvimento microbiano. Essa hipótese é baseada na afirmativa de Van Soest (1994) de que alimentos com alta concentração de pectina, em comparação a fontes tradicionais de amido, podem proporcionar melhor padrão de fermentação ruminal.

A eficiência da síntese de proteína microbiana não foi afetada $(\mathrm{P}>0,05)$ pela inclusão de palma na dieta. A média da ESPBmicr encontrada foi de 115,38 g de PBmic/kg de NDT consumido, próxima ao valor sugerido pelo NRC (2001), de $130 \mathrm{gPBmic} / \mathrm{kg}$ de NDT. Essa ausência de variação na síntese de proteína microbiana pode estar relacionada ao perfeito balanceamento energético-protéico entre as dietas. A eficiência de síntese de proteína microbiana não foi influenciada pela inclusão de palma nas dietas, mesmo com a redução no consumo de NDT $(12,52 ; 13,81 ; 12,24$; $11,46 ; 10,11 \mathrm{~kg} / \mathrm{dia})$ pelos animais do experimento. Melo (2004) observou, no entanto, redução linear para ESPBmicr $(128,01 ; 140,81 ; 111,12 ; 105,92$ e 99,66 gPBmic/kg de NDT) ao avaliarem níveis crescentes de inclusão de caroço de algodão em dietas com palma forrageira para vacas holandesas e atribuíram esses resultados ao aumento no consumo de NDT pelos animais.

Os resultados da análise de regressão quanto às excreções de uréia na urina e de uréia e $\mathrm{N}$-uréico no plasma (Tabela 4) apontaram efeito linear decrescente $(\mathrm{P}<0,05)$ dos níveis de palma na dieta, o que pode estar relacionado à diminuição linear no consumo de MS (20,93; 21,87; 20,17; 18,6; e 16,4 kg/ dia) e PB pelos animais. Essa redução na disponibilidade de oferta da fonte de proteína nas dietas pode ter contribuído para que ocorresse gradual aporte de nitrogênio no rúmen, refletindo diretamente em menores perdas e excreções de uréia na urina e em redução da concentração de uréia no plasma. Apesar dessa redução, a disponibilidade de $\mathrm{N}$ foi suficiente para atender às necessidades dos microrganismos ruminais, possivelmente em virtude do sincronismo da oferta crescente de CNF na palma (Tabela 2).

$\mathrm{O}$ aumento dos níveis de palma nas dietas melhorou a eficiência de utilização da amônia no rúmen, refletindo em menor concentração de UP e NUP, pois, segundo Butler et al. (1996) e Oliveira et al. (2001), concentrações de NUP superiores a $19 \mathrm{mg} / \mathrm{dL}$ representam o limite para a perda de nitrogênio dietético em vacas leiteiras. Todas as dietas apresentaram valores inferiores ao limite crítico proposto na literatura (Tabela 4), indicando que a adição da palma na dieta não provocou perdas de proteína dietética. 
Tabela 4 - Excreções de uréia na urina (EUU) e concentrações de uréia (UP) e N-uréico (NUP) no plasma, de uréia (UL) e n-uréico no leite (NUL) e de glicose no plasma (GP) de vacas holandesas alimentadas com dietas contendo palma forrageira em substituição ao milho e ao feno de tifton

Table 4 - Urea excretion in urine (UEU), urea concentration in plasma (UP) and urea nitrogen in plasma (UNP), urea in milk (UM), urea nitrogen in milk (UNM) and glucose in plasma (GP) according to different levels of forage cactus in the diet

\begin{tabular}{|c|c|c|c|c|c|c|c|c|c|}
\hline & \multicolumn{5}{|c|}{$\begin{array}{c}\text { Nível de inclusão de palma (\%MS) } \\
\text { Forage cactus level }(\% D M)\end{array}$} & \multirow[t]{2}{*}{$\mathrm{CV}(\%)$} & \multirow[t]{2}{*}{ ER } & \multicolumn{2}{|c|}{$\mathrm{P}$} \\
\hline & 0,0 & 12,0 & 25,0 & 38,0 & 51,0 & & & $\mathrm{~L}$ & $\mathrm{Q}$ \\
\hline $\begin{array}{l}\mathrm{EUU}(\mathrm{mg} / \mathrm{kgPV} \\
U E U(m g / \mathrm{kg} B W)\end{array}$ & 561,30 & 463,22 & 459,87 & 339,76 & 335,82 & 30,08 & 1 & 0,00 & NS \\
\hline $\begin{array}{l}\mathrm{UP}(\mathrm{mg} / \mathrm{dL}) \\
U P(m g / d L)\end{array}$ & 40,29 & 29,35 & 30,64 & 26,19 & 23,32 & 14,96 & 2 & 0,00 & NS \\
\hline $\begin{array}{l}\operatorname{NUP}(\mathrm{mg} / \mathrm{dL}) \\
U N P(m g / d L)\end{array}$ & 18,77 & 13,67 & 14,27 & 12,20 & 10,86 & 14,96 & 3 & 0,00 & NS \\
\hline $\begin{array}{l}\mathrm{UL}(\mathrm{mg} / \mathrm{dL}) \\
M U(m g / d L)\end{array}$ & 33,47 & 25,23 & 33,24 & 22,55 & 27,39 & 24,16 & $\hat{\mathrm{y}}=28,37$ & NS & NS \\
\hline $\begin{array}{l}\text { NUL }(\mathrm{mg} / \mathrm{Dl}) \\
U N M(m g / d L)\end{array}$ & 15,59 & 11,75 & 15,49 & 10,51 & 12,76 & 24,16 & $\hat{y}=12,83$ & NS & NS \\
\hline $\begin{array}{l}\mathrm{GP}(\mathrm{mg} / \mathrm{dL}) \\
G P(m g / d L)\end{array}$ & 48,69 & 53,33 & 55,03 & 43,98 & 52,87 & 8,73 & $\hat{y}=50,78$ & NS & NS \\
\hline
\end{tabular}

NS = não-significativo (not significant); $\mathrm{P}=$ palma (forage cactus).

$1=\hat{y}=544,836-0,0447 \mathrm{P}\left(\mathrm{r}^{2}=0,91\right) ; 2=\hat{\mathrm{y}}=37,219-0,2879 \mathrm{P}\left(\mathrm{r}^{2}=0,83\right) ; 3=\hat{\mathrm{y}}=17,3434-0,1342 \mathrm{P}\left(\mathrm{r}^{2}=0,83\right)$.

De acordo com Fergunson et al. (1993) e Garcia-Bajalil et al. (1998), dietas com excesso de PB ou PDR, ausência de carboidratos fermentáveis ou assincronia entre degradação de carboidratos e disponibilidade de energia promovem grande concentração de uréia no sangue e/ou excreção de uréia no leite e na urina, o que não foi observado neste experimento, possivelmente em virtude do correto balanceamento protéico das dietas experimentais e da presença de CNF da palma, que promoveram melhor sincronismo na degradação desses nutrientes.

As excreções médias diárias de uréia e $\mathrm{N}$-uréico no leite não foram influenciadas $(\mathrm{P}>0,05)$ pela inclusão de palma nas dietas. O intervalo dos valores de NUP $(10,86$ e $18,77 \mathrm{mg} / \mathrm{dL})$ e NUL (10,51 e 15,59mg/dL) neste experimento corrobora os relatos da literatura sobre similaridade dessas concentrações. Hristov et al. (2004) verificaram valores muitos próximos entre NUP e NUL em vacas alimentadas com dietas com fonte adequada de proteína degradável no rúmen (14,7 e $13,1 \mathrm{mg} / \mathrm{dL}$, respectivamente). Soares et al. (2005) atribuíram esse fato à concentração plasmática de uréia, que é positivamente relacionada à ingestão de $\mathrm{N}$ e equilibra-se rapidamente com os compartimentos líquidos do organismo e no leite, contribuindo com a proximidade desses valores em suas concentrações.

A variação linear nas concentrações de UP e NUP em relação a UL e NUL pode ser explicada pelo fato de UL e NUL serem variáveis e refletirem o conteúdo médio de uréia e nitrogênio nos períodos da manhã e da tarde (hora de ordenha e coleta do leite). Por outro lado, as concentrações de UP e NUP representam o conteúdo de uréia e nitrogênio no plasma somente no momento em que a amostra de sangue foi coletada (4 horas após a primeira refeição). Esses resultados corroboram os verificados por Gustafsson \& Palmquist (1993) e Kauffman \& St.Pierre (2001), que também demonstraram ocorrer variações entre NUP e NUL 2 a 4 horas após a alimentação em vacas leiteiras. Esses autores observaram que o pico de uréia no soro variou de 1,5 a 2,0 horas após o pico do nitrogênio amoniacal no rúmen.

A substituição parcial do volumoso (feno de capim tifton) pela palma forrageira na dieta proporcionou nível de FDN próximo ao mínimo estabelecido pelo NRC (2001) para manutenção adequada da relação acetato:propionato, o que, possivelmente, não influenciou a concentração plasmática de glicose entre os tratamentos, que apresentou valor médio de $50,78 \mathrm{mg} / \mathrm{dL}$, similar aos resultados determinados por Broderick et al. (2002), de 49,45 e 57,65 mg/dL, em vacas leiteiras alimentadas com diferentes fontes de carboidratos como suplemento alimentar.

\section{Conclusões}

O milho pode ser substituído integralmente e o feno parcialmente $(41,0 \%)$ pela palma forrageira em dietas para vacas holandesas com produção média de $20 \mathrm{~kg} / \mathrm{dia}$, pois a substituição não alterou a produção de proteína microbiana nem ocasionou perdas do nitrogênio dietético via excreção de uréia. 


\section{Literatura Citada}

AGRICULTURAL RESEARCH COUNCIL - ARC. The nutrient requirements of ruminant livestock. Farnham Royal: Commonwealth Agricultural Bureaux, 1980. 351p.

ARNAUD, B.L.; VÉRAS, A.S.C.; FERREIRA, M.A. et al. Efeito da substituição do feno de capim-tifton e do farelo de milho pela palma forrageira e pelo farelo de soja sobre a ingestão de alimentos e parâmetros. Acta Science. Animal Science, v.27, n. 4, p.475-482, 2005.

BRODERICK, G.A.; CLAYTON, M.K. A statistical evaluation of animal and nutritional factors influencing concentrations of milk urea nitrogen. Journal of Dairy Science, v.80, p.29642971, 1997.

BRODERICK, G.A.; MERTENS, D.R.; SIMONS, R. Efficacy of carbohydrate sources for milk production by cows fed diets based on alfafa silage. Journal of Dairy Science, v.85, p.17671776,2002

BRODERICK, G.A. Effects of varying dietary protein and energy levels on the production of lactating dairy cows. Journal of Dairy Science, 86, p.1370-1381, 2003.

BUTLER, W.R.; CALAMAN, J.J.; BEAM, S.W. Plasma and milk urea nitrogen in relation to pregnancy rate in lactating dairy cattle. Journal of Animal Science, v.74. p.858-865,1996.

CHEN, X.B.; GOMES, M.J. Estimation of microbial protein supply to sheep and cattle based on urinary excretion of purine derivatives - an overview of technical details. Aberdeen: Rowett Research Institute/International Feed Research Unit, 1992. 21p. (Occasional Publication).

FERGUNSON, J.D.; GALLIGAN, D.T.; BLANCHARD, T. et al. Serum urea nitrogen and conception rate: the usefulness of test information. Journal of Dairy Science, v.76, p.37423746,1993

FUNDAÇÃO DE INFORMAÇÕES PARA O DESENVOLVIMENTO DE PERNAMBUCO - FIDEPE. Monografias municipais. São Bento do Una; Recife, 1982. 80p.

FUJIHARA, J.L.; ORSKOV, E.V.; REEDS, P.J. et al. The effect of protein infusion on urinary excretion of purine derivatives in ruminants nourished by intragastric nutrition. Journal Agriculture Science, v.109, p.7-12, 1987

GARCIA-BAJALIL, C.M.; STAPLES, C.R.; RISCO, A.A. et al. Protein degradability and calcium salts of long-chain fatty acids in the diets of lactating dairy cows: productive responses. Journal of Dairy Science, v.81, p.1374-1384,1998.

GIESECKE, D.; EHRENTREICH, L.; STANGASSINGER, M. Mammary and renal excretion of purine metabolites in relation to energy intake and milk yield in dairy cows. Journal of Dairy Science, v.77, p.2376-2381, 1994

GONDA, H.L.; LINDEBERG, J.E. Effect of diet on milk allantoin and its relationship with urinary allantoin in dairy cows. Journal of Dairy Science, v.80, p.364-373, 1997.

GUSTAFSSON, A.H.; PALMQUIST, D.L. Diurnal variation of rumen ammonia, serum urea, and milk urea in dairy cows at high and low yields. Journal of Dairy Science, v.76, p.475-484, 1993.

HRISTOV, A.N.; ETTER, R.P.; ROPP, J.K. et al. Effect of dietary crude protein level and degradability on ruminal fermentation and nitrogen utilization in lactating dairy cows. Journal of Animal Science, v.82, p.3219-3229, 2004

JOHNSON, L.M.; HARRISON, J.H.; RILEY, R.E. Estimation of the flow of microbial nitrogen to the duodenum using urinary uric acid or allantoin. Journal of Dairy Science, v.81, p.24082420,1998

JONKER, J.S.; KOHN, R.A.; ERDMAN, R.A. Using milk urea nitrogen to predict nitrogen excretion and utilization efficiency in lactating dairy cows. Journal of Dairy Science, v.81, p.2681-2692, 1998.

KAUFFMAN, A.J.; ST. PIERRE, N.R. The relationship of milk urea nitrogen to urine nitrogen excretion in Holstein and Jersey cows. Journal of Dairy Science, v.84, p.2284-2294, 2001.
MENDONÇA, S.S.; CAMPOS, J.M.S.; VALADARES FILHO, S.C. et al. Balanço de compostos nitrogenados, produção de proteína microbiana e concentração plasmática de uréia em vacas leiteiras alimentadas com dietas a base de cana-de-açúcar. Revista Brasileira de Zootecnia, v.33, n.2, p.493-503, 2004.

MELO, A.A.S.; FERREIRA, M.A.; VÉRAS, A.S.C. et al. Substituição parcial do farelo de soja por uréia e palma forrageira em dietas para vacas em lactação. Digestibilidade. Acta Scientiarum. Animal Sciences, v.25, n.2, p.339-345, 2003.

MELO, A.A.S. Caroço de algodão como fonte de fibra e proteína em dietas a base de palma forrageira para vacas em lactação. Universidade Federal Rural de Pernambuco, 2004. 83p. Tese (Doutorado em Zootecnia) Universidade Federal Rural de Pernambuco, 2004.

NATIONAL RESEARCH COUNCIL - NRC. Nutrient requirements of the dairy cattle. 7.ed. Washington: D.C., 2001. 381p.

NOUSIAINEN, J.; SHINGFIELD, K.J.; HUHTANEN, P. Evaluation of milk urea nitrogen as a diagnostic of protein feeding. Journal of Dairy Science, v.87, p.386-398, 2004.

OLIVEIRA, A.S.;VALADARES, R.F.D.; VALADARES FILHO, S.C. et al. Produção de proteína microbiana e estimativas das excreções de derivados de purinas e de uréia em vacas lactantes alimentadas com rações isoprotéicas contendo diferentes níveis de compostos nitrogenados não-protéicos. Revista Brasileira de Zootecnia, v.30, n.5, p.1621-1629, 2001

PEREZ, J.F.; BALCELLS, J.; GUADA, J.A. et al. Determination of rumen microbial-nitrogen production in sheep: a comparison of urinary purine excretion with methods using ${ }^{15} \mathrm{~N}$ and purine bases as markers of microbial-nitrogen entering the duodenal. British Journal of Nutrition, v.75, p.699-709, 1996.

ROSELER D.K.; FERGUSON, J.D.; SNIFFEN, C.J. et al. Dietary protein degradability effects on plasma and milk urea nitrogen and milk nonprotein nitrogen in Holstein cows Journal of Dairy Science, v.76, p.525-534,1993.

SANTOS, F.A.P.; HUBER, J.T.; THEURER, C.B. et al. Milk yeld and composition of lactating cows fed steam-flaked sorghum and graded concentration of ruminaly degradable proteins. Journal of Dairy Science, v.81, n.1, p.215-220, 1998.

SANTOS, G.T.; CAVALIERI, F.L.B.; MODESTO, E.C. Recentes avanços em nitrogênio não protéico na nutrição de vacas leiteiras. In: SIMPÓSIO INTERNACIONAL DE BOVINOCULTURA DE LEITE: Novos conceitos em nutrição, 2., 2001, Lavras. Anais... Lavras: Universidade Federal de Lavras, 2001. p.199-228.

SILVA, R.M.N.; VALADARES, R.F.D.; VALADARES FILHO, S.C. et al. Uréia para vacas em lactação. 2. Estimativa do volume urinário, da produção microbiana e da excreção de uréia. Revista Brasileira de Zootecnia, v.30, n.6, p.1948-1957, 2001

SNIFFEN, C.J.; ROBINSON, P.H. Microbial growth and flow as influenced by dietary manipulations. Journal of Dairy Science, v.70, p.425-441, 1987.

SOARES, C.A.; CAMPOS, J.M.S.; VALADARES, R.F.D. et al. Produção de proteína microbiana e parâmetros ruminais em vacas leiteiras alimentadas com farelo de trigo. Revista Brasileira de Zootecnia, v.34, n.1, p.345-350, 2005.

SOUZA, A.L.; GARCIA, R.; VALADARES, R.F.D. et al. Casca de café em dietas para vacas em lactação: balanço de compostos nitrogenados e síntese de proteína microbiana. Revista Brasileira de Zootecnia, v.35, n.4, p.1860-1865, 2006.

UNIVERSIDADE FEDERAL DE VIÇOSA - UFV.SAEG - Sistema de análise estatística e genética. versão 8.0 . Viçosa, MG, 1998. 150p. (Manual do usuário).

VALADARES, R.F.D.; GONÇALVES, L.C.; SAMPAIO, I.B. et al. Níveis de proteínas em dietas de bovinos. 4. concentrações de amônia ruminal e uréia plasmática e excreções de uréia e creatinina. Revista Brasileira de Zootecnia, v.26, n.6, p.1270-1278, 1997.

VALADARES, R.F.D.; BRODERICK, G.A.; VALADARES FILHO, S.C. et al. Effect of replacing alfalfa silage with high moisture 
corn on ruminal protein synthesis estimated from excretion of total purine derivatives. Journal of Dairy Science, v.82, n.12, p.2686-2699, 1999.

VALADARES FILHO, S.C.; CABRAL, L.S. Aplicação dos princípios de nutrição de ruminantes em regiões tropicais. In: REUNIÃO ANUAL DA SOCIEDADE BRASILEIRA DE ZOOTECNIA, 39. 2002, Recife. Anais... Sociedade Brasileira de Zootecnia, 2002. (CD-ROM).

VAGNONI, D.B.; BRODERICK, G.A.; CLAYTON, M.K. et al. Excretion of purine derivatives by Holstein cows abomasally infused with Incremental amounts of Purines. Journal of Dairy Science, v.80, p.1695-1702,1997.

Van SOEST, P.J. Nutritional ecology of the ruminant. 2.ed. New York: Cornell University Press, 1994. 476p.
VERBIC, J.; CHEN, X.B.; MACLEOD, N.A. et al. Excretion of purine derivatives by ruminants. effect of microbial nucleic acid infusion on purine derivatives excretion by steers. Journal Agriculture Science, v.114, n.3, p.243-248, 1990.

ZEOULA, L.M.; CALDAS NETO, S.F.; BRANCO, A.F. et al. Mandioca e resíduos das farinheiras na alimentação de ruminantes: $\mathrm{pH}$, concentração de $\mathrm{N}-\mathrm{NH}_{3}$ e eficiência microbiana 1. Revista Brasileira de Zootecnia, v.31, n.3, p.1582-1593, 2002 (supl.). 